Para enlazar con este artículo / To link to this article:

http://dx.doi.org/10.14198/fem.2018.32.10

Para citar este artículo / To cite this article:

Abellán, Rocío. «Habitar y extrañar. La fenomenología del hogar y la arquitectura autobiográfica». En Feminismo/s, 32 (diciembre 2018): 259-286. Dosier monográfico: MAS-MES: Mujeres, Arquitectura y Sostenibilidad - Medioambiental, Económica y Social, coord. María-Elia Gutiérrez-Mozo, DOI: 10.14198/fem.2018.32.10

\title{
HABITAR Y EXTRAÑAR. LA FENOMENOLOGÍA DEL HOGAR Y LA ARQUITECTURA AUTOBIOGRÁFICA
}

\section{DWEEL AND SHOCK. THE PHENOMENOLOGY OF HOME AND THE AUTOBIOGRAPHICAL ARCHITECTURE}

\author{
Rocío ABELLÁN \\ Doctora en Historia del Arte \\ Plataforma de educación cultural Taller Multinacional \\ mrocio.abellan@gmail.com \\ orcid.org/0000-0003-0533-4213
}

\section{Resumen}

La casa es uno de los temas más recurrentes y que más resonancia han tenido en el arte del siglo XX y comienzos del XXI, tanto en su dimensión estética como fenomenológica. Partiendo de esta realidad, el presente artículo se propone analizar la genealogía de la arquitectura doméstica, desde una óptica femenina, para evidenciar la transformación de la casa y sus corolarios en un espacio-arma a la vez político y catártico. A través de una aproximación sociológica, analítica y de género, esta investigación abordará la arquitectura doméstica como una construcción tan política como ontológica. Así, las obras de las artistas analizadas abrirán los paradigmas representacionales relacionados con la construcción doméstica a nuevas estrategias de figuración, capaces de atomizar la casa como un espacio puramente arquitectónico, para concebirlo como un espacio taxativamente emocional.

Palabras clave: feminismo, sostenibilidad, memoria, arquitectura, casa.

\begin{abstract}
The house is one of the most recurrent subjects and with the most resonance in the art of the 20th century and the beginning of the 21st, both in its aesthetic and

Los contenidos de la revista se publican bajo una licencia de Creative Commons Reconocimiento 4.0 Internacional (CC BY 4.0)
\end{abstract}

Feminismo/s 32, diciembre 2018, pp. 259-286 
phenomenological aspect. According to this reality, this paper aims to analyze the genealogy of domestic architecture, from a feminine point of view, to demonstrate the transformation of the house and its corollaries in a political and cathartic spaceweapon. Throughout a sociological, analytical and gender critical approach, this research will broach the domestic architecture as a political and ontological structure.

Thus, the works of the analyzed artists in this research will open the representational paradigms to new strategies of figuration, related to domestic construction. These strategies will be capable of atomizing the house as a purely architectural space, to conceive it as a strictly emotional space.

Keywords: Feminism, sustainability, memory, architecture, home.

\section{LA FENOMENOLOGÍA DE LA CASA}

La casa es, en su más precisa definición, una estructura arquitectónica que habitar. Proporciona un refugio al ser humano al tiempo que le ofrece cobijo y el espacio necesario sobre el que desplegar su actividad vital. De forma paralela, la casa es una construcción simbólica que acoge todo un imaginario referido a la familia, la intimidad, los sueños y los secretos del individuo que mora en ella, al tiempo que es capaz de albergar formas de violencia, desapego y trauma.

En contraposición al espacio público, el interior de la casa garantiza la existencia de un microcosmos que, a modo de refugio, comenzamos a habitar desde el comienzo de nuestra vida. La persistencia temporal de la arquitectura doméstica, tanto a nivel histórico como individual, da cuenta de su importancia, cuya génesis radica en la expresión de la casa como centro de la cosmogonía del ser humano. Desde ella y en ella, se hilvanan todo tipo de historias personales e íntimas, directamente relacionadas con el habitar en un sentido tanto pragmático como metafísico. Desde la construcción de las cabañas prehistóricas, edificadas en función de la escala anatómica del hombre, la identificación entre la vivienda y el cuerpo humano es ancestral (Ramírez 14), tanto es así que la relación identitaria que se establece entre el sujeto y la casa es incontestable. La genealogía de la casa únicamente puede ser concebida al amparo de la evolución social, de ahí que podamos considerar la casa como una entidad viva, capaz de evolucionar y reinventarse a lo largo

Feminismo/s 32, diciembre 2018, pp. 259-286 
de la historia de la humanidad. En consecuencia, podríamos afirmar que la casa se revela como una encarnación del propio sujeto.

La casa ha sido, además, a veces escenario, a veces protagonista, de numerosas obras literarias, teatrales y fílmicas como La caída de la casa Usher, de Edgar Allan Poe, La casa de Bernarda Alba, de Federico García Lorca, o Psicosis, de Alfred Hitchcock. Sin embargo, es probable que haya sido la película de Victor Fleming, El Mago de Oz, la que haya contribuido en mayor medida a reforzar la superioridad del hogar y a perpetuar el mito contemporáneo de la casa como un espacio de seguridad y pertenencia (Perry 7). Absoluta protagonista del metraje, la casa aparece como el espacio de la tediosa familiaridad de la que es necesario escapar para emprender un viaje iniciático en el que Dorothy, la protagonista, a modo de una moderna Ulises, vivirá las más estremecedoras aventuras para certificar, una vez haya regresado a su hogar, que «se está mejor en casa que en ningún sitio» (Fleming 1939).

A diferencia de la casa como mera construcción arquitectónica, las características asociadas a los beneplácitos de la vida doméstica que se le suponen vernáculas son relativamente modernas, ya que no se forjaron hasta el siglo XVII. Hasta entonces, la casa se había caracterizado por poseer una doble función: dar cabida a la vida familiar y a la vida pública. Tras el final de la Edad Media se sucedieron una serie de transformaciones económicas, religiosas, urbanísticas y sociales que propiciaron una nueva conciencia con respecto al individuo, a la casa y a su forma de habitarla.

En concreto, se puede afirmar que fue en los Países Bajos donde tuvo lugar el nacimiento de la casa moderna, caracterizada por una renovada conciencia del espacio privado, que configuró el hogar como un espacio íntimo y familiar. En adelante, la casa moderna se va a entender como un espacio arquitectónico privado destinado a albergar al grupo familiar que, en su íntimo habitar, creará toda una serie de conexiones, afectos y pertenencias que imbuirán a la casa de una impronta doméstica y hogareña. Tras su aparición, esta nueva concepción de la casa como hogar se exportará a otros países del norte de Europa como Francia, Inglaterra o Alemania, donde ya se andaba teorizando al respecto del término Stimmung. El Stimmung se refería a la sensación de intimidad que creaban una habitación y sus elementos y no tenía tanto que ver con la funcionalidad cuanto con la forma en que la habitación expresaba el carácter y el aura de su propietario (Rybczynski 53).

Feminismo/s 32, diciembre 2018, pp. 259-286 
La creciente importancia que se otorgó al ámbito doméstico en los Países Bajos fue consecuencia de diferentes factores que hicieron que las condiciones de vida en esta zona geográfica fuesen diferentes de las del resto de Europa en el siglo XVII. Mientras que la mayor parte de Europa se encontraba sumida en una profunda crisis, los Países Bajos fueron la única nación que entró en una etapa de esplendor conocida como la Edad de Oro neerlandesa. Esto se debió a varios factores: por un lado, su política económica mercantilista hizo del comercio su principal fuente de riqueza, que dio lugar a una burguesía que abarcaba a gran parte de la población. A esta ya de por sí favorable situación, debemos añadir que Holanda fue la primera república europea gobernada por un jefe de estado con poderes limitados. Además, el calvinismo se convirtió en la religión del Estado y ejerció una gran influencia en la vida cotidiana al aportar un sentimiento de serenidad y moderación que afectará al modo de vida de los holandeses. Todas estas circunstancias dieron lugar a una sociedad cuya sencillez se expresaba en todos los ámbitos de su vida cotidiana.

La favorable posición de los neerlandeses los llevó a emprender notables cambios con respecto a la casa: cambió la distribución espacial de la vivienda derivada de la separación de los espacios en función de las actividades domésticas; se favoreció la apertura de establecimientos dedicados a los negocios, por lo que el trabajo se separó de la casa; y se produjo un cambio de mentalidad, producto de la austeridad calvinista, con respecto a los sirvientes domésticos, que se redujeron en número en comparación con el resto de países de Europa. La confluencia de estos condicionantes tuvo como consecuencia directa la comprensión de la casa como reducto de vida hogareña, más tranquila y privada que, a su vez, favoreció el reconocimiento tanto del yo, como de la familia y la domesticidad. Definitivamente, «la casa había cambiado tanto física como emocionalmente» (Rybczynski 85), es decir, había dejado de ser una mera construcción arquitectónica para pasar a convertirse en un hogar. Estos cambios orquestados al respecto de la fenomenología de la casa derivaron en la comprensión de ésta como un espacio eminentemente femenino en el que las mujeres neerlandesas llevaban a cabo las tareas del mantenimiento, cuidado y administración del hogar.

Dada la importancia que adquiere el espacio doméstico y la figura femenina como entidad asociada y como parte indispensable del mismo, resulta lógico que los artistas holandeses cultivasen la pintura de género, o pintura

Feminismo/s 32, diciembre 2018, pp. 259-286 
de interior, donde se reflejan, de forma apacible y sosegada, los beneplácitos de la vida hogareña (De Azcárate Ristori, Pérez Sánchez y Ramírez Domínguez 514). En este tipo de pintura, el interior doméstico pasa de ser un mero trasfondo que posibilita la escena representada, a configurarse como el protagonista, casi absoluto, de la figuración. En este sentido, y al respecto de la feminización de la casa, es fundamental la figura de Johannes Vermeer, debido a la relevancia que adquiere la mujer en sus cuadros. En sus obras, extremadamente realistas, una multitud de personajes femeninos aparecen absortos en el quehacer de sus labores diarias, como el bordado o la lectura de una carta. Estas composiciones se presentan como verdaderas naturalezas muertas (Díaz 120) en las que la mujer aparece como parte de la ornamentación del interior, lo que contribuye a reafirmar la reiterada identificación de la mujer con el espacio doméstico y el papel protagónico que adquiere el mismo en la representación.

En el transcurso de los siglos XVIII y XIX se terminó de asentar la nueva concepción del hogar como locus familiar e íntimo y, sobre todo, la identificación de éste con el género femenino. En adelante, esta identificación favoreció una lectura de género del espacio privado, relacionada con la interioridad, el decoro y la dependencia, características asociadas a la mujer; y del público, relacionado con el trabajo, la autoridad y la libertad, cualidades asociadas al hombre. Estas asociaciones simbólicas propiciaron que el espacio doméstico no pudiera concebirse con independencia del género al que se asociaba y delimitaron «unos criterios de actuación, unas expectativas, unas virtudes, en fin, un modo de ser que será el que corresponda a 'lo femenino'» (Molina 116).

El hogar comenzó así a conformarse en torno a la idiosincrasia femenina. En el hogar se criaba a los hijos y se desempeñaban las labores propias del mantenimiento de la familia: cocinar, remendar, limpiar, lavar y parir. La reclusión de la mujer dentro de la órbita de lo doméstico tomó un cariz más represivo a raíz de la consolidación del pensamiento ilustrado, que trajo consigo la exclusión de la mujer como ser racional y, por tanto, ésta quedó reducida al ámbito de la naturaleza. Esta identificación, defendida por pensadores como Jean-Jacques Rousseau, operó como una categorización discriminatoria que favoreció la creencia de que la mujer, como naturaleza, debía ser «domesticada»y, por tanto, contenida y recluida en el hogar. Más tarde, en la época victoriana, a la ya de por sí existente reclusión de la mujer en la

Feminismo/s 32, diciembre 2018, pp. 259-286 
esfera del hogar, se unió una sobre represión moral de la época que afectó sobremanera a la mujer. Durante estos años tuvo lugar la emergencia de la histeria como patología femenina que exigió, sostiene Michel Foucault, «una medicalización minuciosa de su cuerpo y su sexo, que se llevó a cabo en nombre de la responsabilidad que les cabría respecto de la institución familiar y de la salvación de la sociedad» (179). Tanto la familia (derivado de famulus, sirviente, esclavo), como el espacio doméstico (derivado de domus, casa, que, a su vez, comprende la acepción de domesticación), conformaron un sistema simbólico a partir del cual aproximarnos a la realidad femenina no sólo desde una perspectiva sociológica, sino también política.

Así, la casa, ese pretendido bastión de lo privado, de lo íntimo y lo doméstico, no es tan sólo una zona de refugio que se alza para protegernos de la esfera pública, sino que es también un símbolo de las disciplinas y el mejor garante del control ideológico y moral de sus ocupantes (García Cortés 70-71). Sólo el sometimiento de la mujer a este sistema simbólico garantiza la sostenibilidad de éste.

\section{LA DECONSTRUCCIÓN DEL ESPACIO DOMÉSTICO}

El binomio mujer-interior doméstico que se forjó desde el siglo XVII y que el pensamiento ilustrado reforzó, impuso una visión normativa de la mujer basada en una visión idealizada y reduccionista de ésta como esposa, madre y ama de casa. Este modelo de mujer, circunscrito al ámbito doméstico, hizo de ésta la única responsable del cuidado de la familia y de la realización de las tareas domésticas. Estas labores, tediosas y repetitivas, cercanas al ritual, fueron la garantía de la sostenibilidad, en primera instancia, del orden doméstico y familiar y, en un segundo plano, de la perpetuación de la maquinaria social impuesta por un sistema social basado en el androcentrismo y en el capitalismo.

Con el cambio de siglo, la llegada de la tecnología al interior doméstico derivó en la mecanización de éste. Sin embargo, este hecho no eximió a las mujeres de sus quehaceres domésticos, sino que persistió la idea de que el arraigo de la mujer al hogar era algo inherente a su propia naturaleza y no una construcción cultural, por lo que el ideal de la mujer como ama de casa se extendió a todas las clases sociales (Bauer 42).

Feminismo/s 32, diciembre 2018, pp. 259-286 
La mecanización del hogar introdujo un cambio notable, no tanto en la relación entre la mujer y el interior del hogar, sino respecto a cómo concebir el interior doméstico en términos de eficiencia. A comienzos del siglo XX se publicaron los primeros tratados de economía doméstica que tenían como objetivo la gestión sostenible de las labores y del cuidado del hogar. Estos tratados estaban destinados exclusivamente a mujeres y exponían, de forma gráfica y didáctica, pautas y consejos para mejorar la eficiencia con respecto al funcionamiento del hogar. Este tipo de escritos parecieron responder a una necesidad de institucionalización de las labores domésticas con el fin de mitigar la brecha existente entre el trabajo masculino, siempre exterior y remunerado, y el trabajo femenino, interior, impuesto y, sin duda, no remunerado.

De entre estas tratadistas destaca Catherine E. Beecher, quien escribió, entre otros ensayos, Un Tratado sobre Economía Doméstica para el Uso de Damas Jóvenes en Casa y en la Escuela y La Casa de la Mujer Americana, este último junto a su hermana Harriet. Tanto las hermanas Beecher como otras autoras de la talla de Ellen Richards o Mary Pattison, formularon los principios de la ingeniería doméstica, resultado de «los esfuerzos de las mujeres por racionalizar y organizar las tareas domésticas y las teorías que se habían elaborado para mejorar la producción industrial de las fábricas» (Amann 172).

El éxito del que disfrutaron estos tratados radicó en que estaban ideados por mujeres para mujeres y, por tanto, trataban la experiencia doméstica desde la perspectiva de las propias interesadas. En estos tratados las amas de casa podían consultar cómo realizar tareas como lavar, cocinar, hacer la comprar u organizar un presupuesto de forma más competitiva y eficaz. A comienzos del siglo XX, y por influencia de Beecher, la economía doméstica comenzó a enseñarse como asignatura en las universidades, coincidiendo con el acceso de las mujeres a la educación superior.

La casa comenzó a entenderse como un espacio activo, una vez que se aceptó que ésta no era únicamente un espacio inerte, de reclusión y de confort, sino también un espacio de trabajo que requería de la mano de obra femenina para su mantenimiento. Esta progresiva reconceptualización del hogar bajo un imperativo tecnológico que, por otro lado, estaba lejos de liberar a la mujer de su reclusión en él, coincidió con un cambio en la industria manufacturera que, una vez acabada la I Guerra Mundial, dirigió su producción a la de aparatos domésticos de la más diversa índole.

Feminismo/s 32, diciembre 2018, pp. 259-286 
Esta reconversión de la producción industrial, que coincidió con la vuelta de las mujeres al hogar tras haber suplido el papel de los hombres en las fábricas durante la contienda, ayudó a paliar las posibles frustraciones que esta situación pudiese originar. Tras su breve salida, la mujer volvió a ser recluida en el hogar, y en este proceso jugaron un papel decisivo las revistas femeninas y los productos domésticos. Desde su aparición, las revistas femeninas reflejaron los diferentes cambios en la condición de la mujer: así, mientras que durante la guerra reforzaron su campaña para atraerlas al trabajo por primera vez, una vez terminada la guerra, las revistas volvieron a vender una domesticidad idílica e instaron a las mujeres a volver al hogar (Wolf 81-82). Del mismo modo, y para suplir el vacío generado por esta vuelta, tanto las revistas como la publicidad se poblaron de anuncios que plasmaban a una feliz y empoderada ama de casa rodeada de todo tipo de productos domésticos que, al tiempo que multiplicaban la eficiencia de sus labores, la convertían en una consumidora compulsiva de todo tipo de artículos para el hogar.

Estas líneas de actuación participaron de las teorías iniciadas por Beecher que idealizaron la reclusión de la mujer y romantizaron la exclusiva feminización del trabajo doméstico. Sin embargo, y a pesar de que históricamente se ha considerado a Catherine E. Beecher como una de las primeras mujeres precursoras de la arquitectura moderna, lo cierto es que sus teorías poseían un trasfondo radicalmente conservador. La sostenibilidad y eficiencia que promovieron estos tratados de economía doméstica estuvo, a todas luces, lejos de ser un sistema legítimo para el desarrollo de la mujer como sujeto autónomo e independiente, más bien perpetuaron la premisa ilustrada de que el lugar de la mujer se encontraba dentro del hogar.

Desde mediados del siglo XX, autoras como Betty Friedan o Mariarosa Dalla Costa denunciaron las falacias de un sistema social que ha definido a la mujer como centro de una organización orquestada en torno a la arquitectura doméstica. Las teorías de Friedan en torno a la mística de la feminidad abrieron el resquicio por el que se introdujo la Tercera Ola Feminista. Esta reaparición del movimiento feminista estuvo centrada en las protestas en torno a la sexualidad, la desigualdad de género, la familia y el hogar. Ambas autoras pusieron el foco de atención en el hecho de que la mujer había sido enclaustrada en la casa, forzada a llevar a cabo un trabajo que se consideraba no cualificado y, por tanto, no remunerado, lo que la dejó estancada en unas condiciones

Feminismo/s 32, diciembre 2018, pp. 259-286 
precapitalistas (Dalla Costa y James 33). A partir de este momento se comenzó a poner en duda que el lugar de pertenencia de la mujer fuera la casa y, bajo la máxima «lo personal es político», estas teorías fomentaron la reinscripción del concepto mismo de lo femenino desde lo femenino no sólo a través del activismo social, sino también de la práctica artística.

De forma coetánea, vio la luz el aclamado artículo de Linda Nochlin en el que la autora se preguntó por qué no había habido grandes mujeres en la historia del arte. Este texto puso el foco en el hecho de que la historia del arte del siglo XX prácticamente había suprimido a las mujeres artistas de sus registros. También se evidenció que, en las contadas ocasiones en las que las mujeres eran citadas, era para retratarlas como productoras de un tipo de obra que dejaba testimonio de la única cualidad derivada de su sexo: la feminidad y, por lo tanto, eran la prueba fehaciente de que las mujeres tenían un estatus menor como artistas (Pollock 63). No era sólo que ellas como entidades productoras y productivas fuesen eludidas, sino que, además, aquello que tenían que decir y desde dónde lo tenían que decir, no era en absoluto trascendente.

Así, la primera fase del arte feminista se centró en cambiar los patrones representacionales que hasta entonces habían dominado la figuración femenina y en dar visibilidad al arte realizado por las mujeres que, hasta el momento, había sido ignorado como parte integrante del relato canónico. En consecuencia, surgieron toda una serie de manifestaciones artísticas que, en ese momento, y a la luz de las teorías de Friedan y Dalla Costa, arrojaron una mirada crítica al respecto de la relación de la mujer con la casa y el trabajo doméstico. Estos trabajos figuraron una ruptura tanto formal como ontológica con respecto a la domesticación hasta entonces sufrida por las mujeres.

El más icónico de todos ellos y el más rupturista, quizá por ser el primero, acaso por ser el de más envergadura, fue la exposición Womanhouse, que se celebró en 1972. Esta exposición colectiva devino como resultado de un programa artístico y feminista iniciado por Judy Chicago y Miriam Schapiro en California. Este Programa de Arte Feminista fue el primer proyecto destinado a la práctica artística realizada por mujeres acerca de su propia realidad. Durante el mismo, veinticuatro mujeres remodelaron una casa en el 533 de Mariposa Street, en Los Ángeles, convirtiéndola en un espacio expositivo en el que estas mujeres reinterpretaron diferentes espacios o habitaciones de su interior (Reckitt y Phelan 21). La Womanhouse se convirtió, así, en una

Feminismo/s 32, diciembre 2018, pp. 259-286 
especie de exorcismo para aquellas mujeres con respecto a las labores que habían venido desarrollando hasta ahora en el ámbito doméstico como planchar, cocinar, coser o fregar. Piezas como Linen Closet de Sandy Orgel, Bridal Staircase de Kathy Huberland, The Kitchen de Robin Weltsch o Menstruation Bathroom de Judy Chicago, convivieron con performances como Waiting de Faith Wilding o Maintenance. Estos trabajos, profunda e irremediablemente biográficos a la vez que políticos, hablaban, en primera persona, de la tiranía de la belleza y del miedo a envejecer, de la realidad que muchas veces se escondía tras las nupcias, de la casa y, en concreto, de la cocina como espacio asociado a la mujer, y de la menstruación como algo natural. Todas estas piezas surgieron del descontento de las mujeres ante la realidad a la que estaban subyugadas y que nacía y moría entre las cuatro paredes de la casa.

Las artistas de la Womanhouse fracturaron la dinámica que, hasta entonces, había cimentado los relatos de la modernidad que adscribían la mujer al hogar y dieron origen a una brecha disruptiva en torno a los espacios codificados bajo el estigma de lo femenino. Al respecto, cabe destacar la evidente comparativa entre las obras de Berthe Morisot, Young Woman Empowdering her Face -1877- y la pieza de Karen Lecoq, Lea's Room [Figs. 1] realizada para la Womanhouse. En ambas obras, una mujer sentada frente a su tocador,
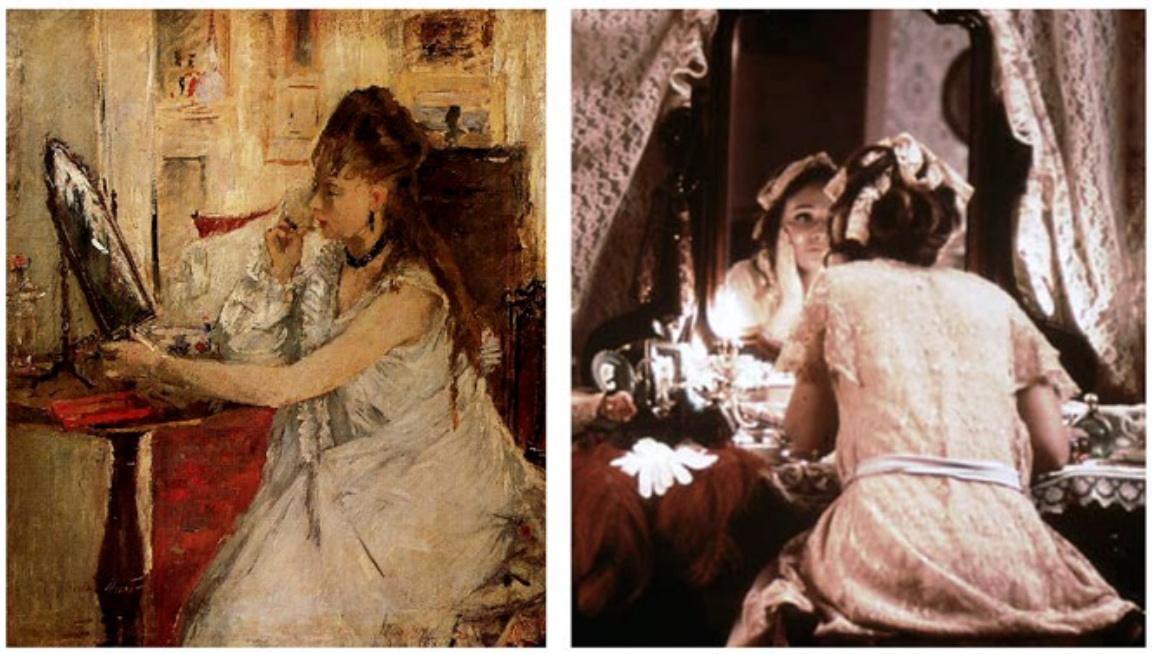

Figura 1.

Feminismo/s 32, diciembre 2018, pp. 259-286 
abarrotado de productos de belleza, se maquilla frente al espejo en un acto eminentemente femenino e íntimo. La pintura de Morisot se produjo desde la sujeción a una realidad que le era propia y que, quizá en ese momento, no se había atrevido a cuestionar; por el contrario, la pieza de Lecoq se concibió como un punto de fricción entre la realidad femenina estandarizada y enclavada en los preceptos de una modernidad anquilosada y la nueva reconfiguración del hogar desde la perspectiva del desencanto y del resentimiento. Siguiendo la senda inaugurada por la Womanhouse, surgieron otras piezas como Death of the Housewife -1974- de Kate Walker, Semiotics of the Kitchen -1975- de Martha Rosler, First Bathroom (Woman Standing) -1978- de Laurie Simmons o el proyecto Feministo: Portrait of the Artist as a Housewife, creado en 1975 para protestar acerca del aislamiento doméstico al que estaban sometidas las mujeres y su exclusión del circuito artístico.

Lo cierto es que la arquitectura de la casa posee una de las simbologías más poderosas de la cultura occidental, ya que incorpora ideologías y jerarquías específicas y, por lo general, dominantes en relación a la casa y a la mujer como sustento de ésta (Torre 51). En definitiva, estas artistas deconstruyeron y reinterpretaron el espacio doméstico que la modernidad había configurado en torno a la feminidad, evidenciando el hogar como un espacio en crisis desde el que quebrantar la relación de subordinación y debilidad históricamente determinada por el género.

\section{LA ARQUITECTURA COMO NARRACIÓN}

Frente a las estrategias deconstructivas que, en torno al espacio doméstico, llevaron a cabo las artistas anteriormente mencionadas, el siglo XX también ha sido testigo de toda una serie de representaciones que, tanto de forma estructural como simbólica, han convertido la arquitectura de la casa y sus corolarios en un espacio experiencial y narrativo basado en presupuestos eminentemente autobiográficos.

Partiendo de esta premisa, en lo que sigue nos vamos a aproximar a una serie de obras que, virando desde discursos universales y reivindicativos, aunque no por ello menos biográficos, hacia otros anclados en la exclusiva experiencia del sujeto individual, han conseguido subvertir, con la misma

Feminismo/s 32, diciembre 2018, pp. 259-286 
cantidad de lirismo que de radicalidad, las nociones mismas de arquitectura y de hogar, así como la asociación mujer-casa.

Bajo esta línea de indagación, la casa ha servido como trasfondo para figurar una realidad femenina que, más allá de la subyugación de la mujer al interior doméstico como sustento de éste, ha lidiado con la toma de conciencia de la mujer respecto a su propia realidad individual. Por tanto, si a partir de la década de los setenta el binomio compuesto por las realidades de la mujer y la casa, hasta ese momento indisoluble, comenzó a ponerse en entredicho, no sería justo obviar el tratamiento que se le ha dado a la casa en el último arte del siglo XX como trasfondo auto expresivo que ha permitido a la mujer exorcizar su propia realidad desde una perspectiva experiencial y retratar una representación sostenible en concordancia con su propia historia personal. En este sentido, es preciso leer la casa como una herramienta mediante la que figurar los abismos interiores de la mujer desde una posición eminentemente autobiográfica.

Así, desde los lienzos de Mary Cassatt o Berthe Morisot que reflejaron la vida cotidiana de una mujer a comienzos del siglo XX, a las obras de artistas como Francesca Woodman o Tracey Emin, podemos evidenciar cómo la deconstrucción que se ha ejercido en torno a la casa y los objetos que la componen también se ha ejercido sobre la mujer misma. Ésta, atravesada por una reflexividad y una interioridad hasta ese momento ignoradas, ha comenzado a ser sujeto activo de su propia representación y ha roto con los cánones anteriormente impuestos al desvirtuar las narrativas convencionales a través de un absoluto desbordamiento de su subjetividad. Como van a poner en evidencia las manifestaciones que pasaremos a detallar a continuación, la casa también se ha convertido en una entidad activa y dinámica, pero no en el sentido que pretendió infundirle Catherine E. Beecher, sino en el que reconoce la arquitectura doméstica como una entidad igualmente reflexiva que se construye a medida que se reflexiona en torno a ella.

Esta proposición ha dado lugar a una arquitectura narrativa que, a partir de la memoria y la reflexión, ha figurado diferentes invocaciones del hogar, que han hecho de éste el escenario lógico de la indagación de la mujer con respecto a su propia identidad y experiencias. Así, la importancia de estas obras radica no sólo en una renovada relación de la mujer con la casa y sus pertenencias, sino en la capacidad de ésta de ser el recinto que da cabida

Feminismo/s 32, diciembre 2018, pp. 259-286 
a su historia personal. Estas prácticas, que han llevado la relación entre la mujer y la casa hacia un territorio ciertamente autobiográfico, han resultado doblemente transgresoras, ya que la disciplina autobiográfica, hasta ese momento, había estado dominada en su práctica totalidad por definiciones androcéntricas que habían figurado al varón heterosexual y de raza blanca como sujeto predominante y reducido a la mujer al territorio de lo otro, al margen del discurso canónico.

La exposición de la autobiografía femenina ha alterado el orden autobiográfico dominante masculino demostrando que la mujer posee una subjetividad propia, a pesar del vigor con el que la cultura patriarcal ha intentado suprimirla (Smith 116) y recluirla en el interior doméstico. Así, ese margen desde el que le es legítimo operar, el hogar, se ha desplegado en un ejercicio de ruptura con respecto a las fronteras de lo público y lo privado y se ha desvelado como lo más íntimo de la mujer y de su espacio propio. Al descubierto ha quedado el interior de la casa, impregnada de la propia vida que se dispersa entre los recovecos de una arquitectura que aparece como la metáfora, como la evocación, del yo autobiográfico.

Este viraje de sentido que ha protagonizado el discurso enraizado en torno al hogar, desde una proposición colectiva y reivindicativa hacia otra individual y subjetiva, está basado en lo que Shirley Neuman ha denominado una «poética de las diferencias», es decir, en el reconocimiento de un «yo» femenino que se concibe, más allá de poseer estructuras discursivas comunes y una poderosa conciencia de grupo, como una matriz de diferencias en y con respecto a sí mismo, además de diferencias con respecto a otros (437). Para Neuman,

la mujer es un sujeto complejo, múltiple, que consta de varias capas y que puede ser agente de cambio [ «with agency»] de los discursos y los mundos que construyen el espacio referencial de su autobiografía, un yo no sólo compuesto [ «constructed»] por diferencias sino capaz de elegir, de inscribir y de actuar. (438)

Por tanto, la topografía del hogar y sus corolarios se ha reconfigurado en un topoanálisis (Bachelard 31), esto es, en el análisis de la representación de los pasajes de la vida íntima a través de la arquitectura de una casa viva, que trasciende el espacio arquitectónico y se cimenta a partir de la experiencia. Así, el hogar se presenta como la resulta de una narrativa que no puede ser

Feminismo/s 32, diciembre 2018, pp. 259-286 
desenredada de la arquitectura ya que, sin aquélla, ésta se desmoronaría y, sin ésta, aquélla no tendría qué habitar (Bal 29).

Este modo de «construir» la casa ha envuelto tanto su arquitectura como los objetos que la habitan en un aura próxima a lo sagrado. Esta caracterización viene determinada por la definición de lo sagrado a la que se aproxima Rudolf Otto, quien define lo sagrado como lo numinoso o misterioso. Para Otto, lo numinoso se refiere a una realidad incognoscible subyacente en todas las cosas y que únicamente se hace consciente «por el peculiar reflejo sentimental que provoca en el ánimo» (21) y, por tanto, no puede mostrarse como tal, sino que únicamente puede hacerse evidente como aquello que imbuye, en este caso, la casa, a través de la transferencia de estos sentimientos que en ella se introyectan y que vinculan a la mujer y la casa en una serie de conexiones que las agitan y las violentan.

Así, las arquitecturas que vamos a explorar a continuación no son ni funcionales ni habitables en el más estricto sentido de los términos. Su habitabilidad se encuentra en un plano más metafórico, que excede su función práctica. Estas arquitecturas se despliegan como espacios para la memoria, las historias familiares, la expresión individual, la violencia y, en algunos casos, la elaboración traumática.

\section{LA CASA COMO SÍNTOMA}

En el espacio discursivo que comprende la arquitectura de la casa se inscriben, como hemos podido comprobar, toda una serie de jerarquías y asociaciones culturales que pueden ser $y$, de hecho, son subvertidas a través de la práctica artística. Desde que en los años setenta se divulgase la premisa feminista «lo personal es político», el terreno artístico ha sido testigo de una proliferación de obras «confesionales» que han tenido bien como trasfondo principal, bien como exclusivo protagonista, a la casa. En ella se han forjado toda una serie de vivencias en primera persona que, enraizadas en lo cotidiano, han establecido una renovada relación entre la mujer y la casa. En este sentido, la casa se configura como una estructura dinámica y permeable a las modulaciones de la historia personal de sus habitantes.

Esta identificación entre la casa y la mujer únicamente puede darse en el habitar. Según defiende Bachelard, es en la casa natal donde se incorporan

Feminismo/s 32, diciembre 2018, pp. 259-286 
en el sujeto las diferentes funciones del habitar, ya que es en ella en la que se asientan los valores de protección y se establecen jerarquías, costumbres y afectividades que quedarán fijados por los recuerdos, por lo que el resto de casas que se habiten sólo serán una proyección de esta primera casa natal y las formas de habitarlas seguirán los patrones establecidos en esa primera habitabilidad (56). De este modo, la casa se convierte en uno de los principales espacios de unión, de identificación y de coherencia entre la arquitectura y la mujer.

Dada su habitabilidad, el interior doméstico, en el que conviven la cotidianidad, los afectos, las pertenencias, lo rutinario y los vínculos personales, constituye uno de los principales espacios biográficos del ser humano. Esta consideración de la casa como autobiografía descansa en la relación entre el territorio y el desbordamiento de la subjetividad y la experiencia femenina, de la que resulta «una espacialidad habitada por discontinuidades, tanto físicas como de la memoria» (Arfuch 31).

Quizá Louise Bourgeois sea una de las artistas que de forma más significativa ha reflexionado acerca de las conexiones entre la casa y la propia vida. Bourgeois ha desplegado un corpus artístico en el que lo doméstico, lo familiar y lo cotidiano conviven con lo amenazador, lo represor y lo claustrofóbico. En la obra de esta artista el hogar y la infancia se aúnan para enunciar un discurso íntimo y personal en el que se cuestiona la jerarquía familiar y en el que la morada se reviste de una extrañeza absolutamente aterradora. La casa es para la artista el escenario de los conflictos que, desde su niñez, determinarán su biografía; un microcosmos determinado por un padre autoritario e infiel, la figura de su amante y su madre, consciente y, por ende, cómplice de la situación. La imagen del dulce hogar de la infancia se convirtió, para Bourgeois, en un escenario de opresión y desprecio, en el que reinaba el despotismo y la crueldad y en el motivo central sobre el que pivotará su creación plástica.

Tanto la vida como la trayectoria artística de Bourgeois han estado marcadas por su autobiografía, siendo la casa natal la arquitectura a la que, de forma incesante, volverá una y otra vez. Es precisamente a través de la práctica artística, plano semejante al ensueño, como Bourgeois es capaz de habitar oníricamente la casa natal, que es, tal y como sugiere Bachelard, más que habitarla en el recuerdo, vivir en la casa desaparecida tal y como lo habíamos soñado (37). Gracias al amplio material biográfico acerca de Louise Bourgeois

Feminismo/s 32, diciembre 2018, pp. 259-286 
del que se dispone y que, por otra parte, ella misma ha facilitado en forma de entrevistas, escritos y documentales, descubrimos los pormenores de un universo interior que, de forma incesante, se proyectará en sus construcciones.

La primera serie de obras relacionadas con la casa, sus Femme Maison, datan de comienzos de los años cuarenta. Se trata de dibujos, óleos y grabados que, más tarde, se convertirán en piezas escultóricas y que participan de, o más bien anticipan, la crítica al binomio mujer-casa, en el que la identidad femenina se diluye en favor de una arquitectura doméstica que la subyuga. En estas obras tempranas, al cuerpo de la mujer desnuda se le ensambla, de forma absolutamente violenta, una casa en la parte superior de su anatomía, llegando en ocasiones a no poder discernir, como sucede en la femme-maison de 1947 [Fig. 2], dónde acaba una y dónde comienza la otra.

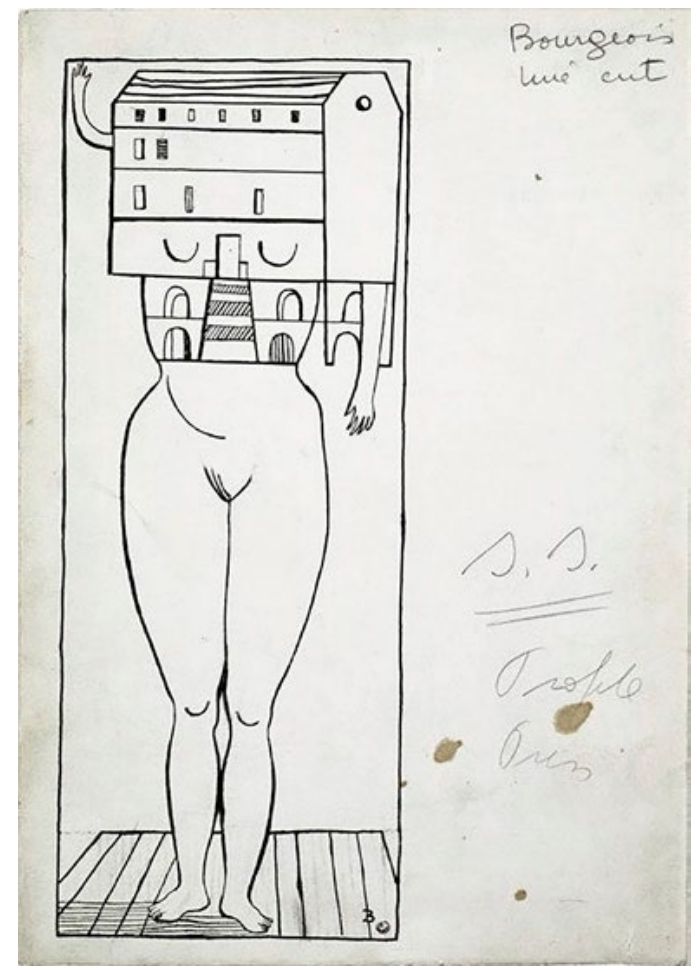

Figura 2.

Feminismo/s 32, diciembre 2018, pp. 259-286 


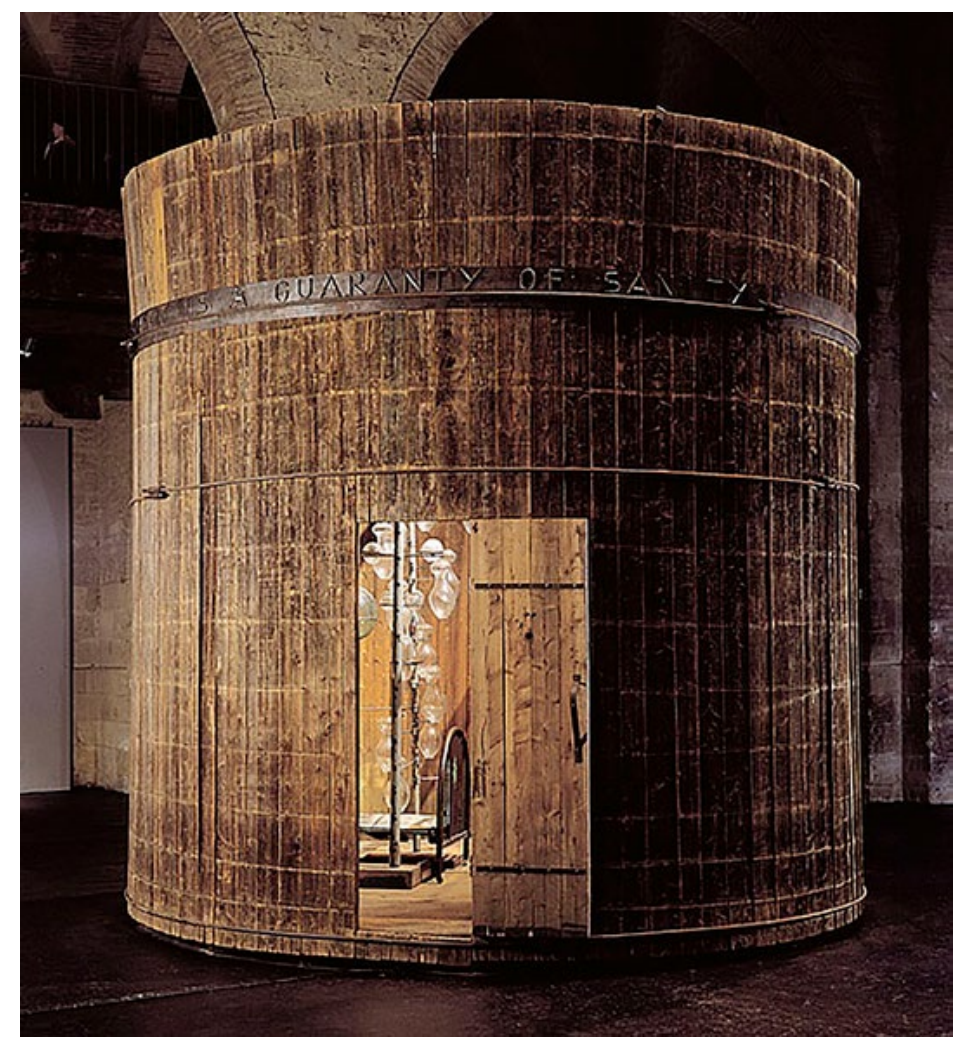

Figura 3.

Sin embargo, será a partir de la década de los noventa del siglo pasado cuando Louise Bourgeois comience a realizar -0 , más bien, a construir- sus icónicas Cells, como Precious Liquids -1992- [Fig. 3] o The Last Climb-2008-, en las que no dejó de trabajar hasta su muerte. En ellas, estructuras que median entre lo escultórico y lo arquitectónico, se repetirá, de forma inagotable, la arquitectura de la casa natal y las experiencias que en ella tuvieron lugar y que condicionaron su infancia, en un continuo ejercicio de agresión-reconciliación consigo misma. En estas celdas, y de acuerdo con Mieke Bal, el nexo entre la escultura y la arquitectura es, precisamente, la narrativa (2). Estas piezas no representan la casa natal de Bourgeois, sino que es la misma

Feminismo/s 32, diciembre 2018, pp. 259-286 
artista quien, a través de la narración autobiográfica, interpreta ese espacio primigenio destinado a albergar los recuerdos de Bourgeois, al tiempo que le sirven de catalizador mediante el que recomponer su infancia.

En estas celdas, Bourgeois transfiere sus cargas emocionales del pasado. La transferencia, según la teoría psicoanalítica, «es una narrativa de la representación que trae el pasado al presente con el fin de revisar la obra» (Bal 83). Esta recuperación del pasado imprime un innegable carácter siniestro en el que objetos cotidianos, oscuros recovecos, habitaciones claustrofóbicas, camas desvencijadas, prendas de ropa que adquieren cualidades fantasmagóricas y arañas gigantes, componen la iconografía personal de la artista.

De forma análoga encontramos el trabajo de la británica Tracey Emin, otra de las artistas contemporáneas que ha construido buena parte de su discurso artístico en torno al espacio doméstico y a los objetos que lo ocupan. Deudora del espíritu subversivo de los Young British Artists - grupo al que perteneció- la trayectoria artística de Emin constituye uno de los ejemplos más destacados en relación a la puesta en escena de su propia vida.

La obra de Emin supone un relevante y extremadamente perturbador documento visual de su experiencia biográfica. En ella, y de una forma absolutamente descarnada, relata traumáticas experiencias de su infancia en el seno de una familia disfuncional: su padre, un inmigrante turcochipriota dividía su tiempo en atender a las dos familias que tenía, una de ellas la compuesta por Emin, su hermano gemelo y su madre. Creció en el hotel que ambos regentaban hasta que un incendio acabó con él. Envar Emin, su padre, acabó por abandonarlos de forma definitiva ante la imposibilidad de hacerse cargo de dos familias, de modo que los tres miembros de la familia se instalaron en una diminuta casa de mantenimiento, propiedad del mismo hotel (Emin 67-133). Las experiencias de su niñez han sido fielmente rememoradas por la artista en Strangeland donde, con una prosa implacable y directa, relata la soledad y las humillaciones vividas durante su infancia. Estos sucesos, junto con su violación ocurrida a la edad de trece años cuando salía de una discoteca durante la Nochevieja de 1976, marcarían a Emin y, por extensión, su carrera, de forma definitiva.

La indagación en torno a lo doméstico y lo familiar que lleva a cabo la artista está construida sobre una arquitectura de la casa y sus corolarios que adquieren una investidura simbólica y que cercan el espacio biográfico en

Feminismo/s 32, diciembre 2018, pp. 259-286 
el que Emin despliega su subjetividad. Los espacios del pasado recreados por Emin actúan como un tropo sustitutivo de un tiempo y un espacio que fue. Esta idea de retorno no sólo va a activar el componente ominoso que adquiere la arquitectura biográfica en la obra de la artista, sino que también va a activar una dimensión terapéutica que deriva de «la necesidad de decir, de la narración como trabajo de duelo» (Arfuch 76).

A través de las arquitecturas recreadas, Tracey Emin deja constancia de la peligrosidad que pueden comprender los espacios domésticos al presentarse como la evocación de un pasado disfuncional, aunque no exento de cierto sentimentalismo. Así, en esta retrospección espacial la artista construye arquitecturas tan frágiles e inestables como monumentales y rudimentarias, en las que evoca experiencias biográficas al tiempo que se redime de ellas. Puede que la más conocida de ellas sea Everyone I Have Ever Slept With-1995- [Fig. 4], más conocida como Tent, una tienda de campaña dentro de la cual había bordado los nombres de todas las personas con las que había dormido alguna

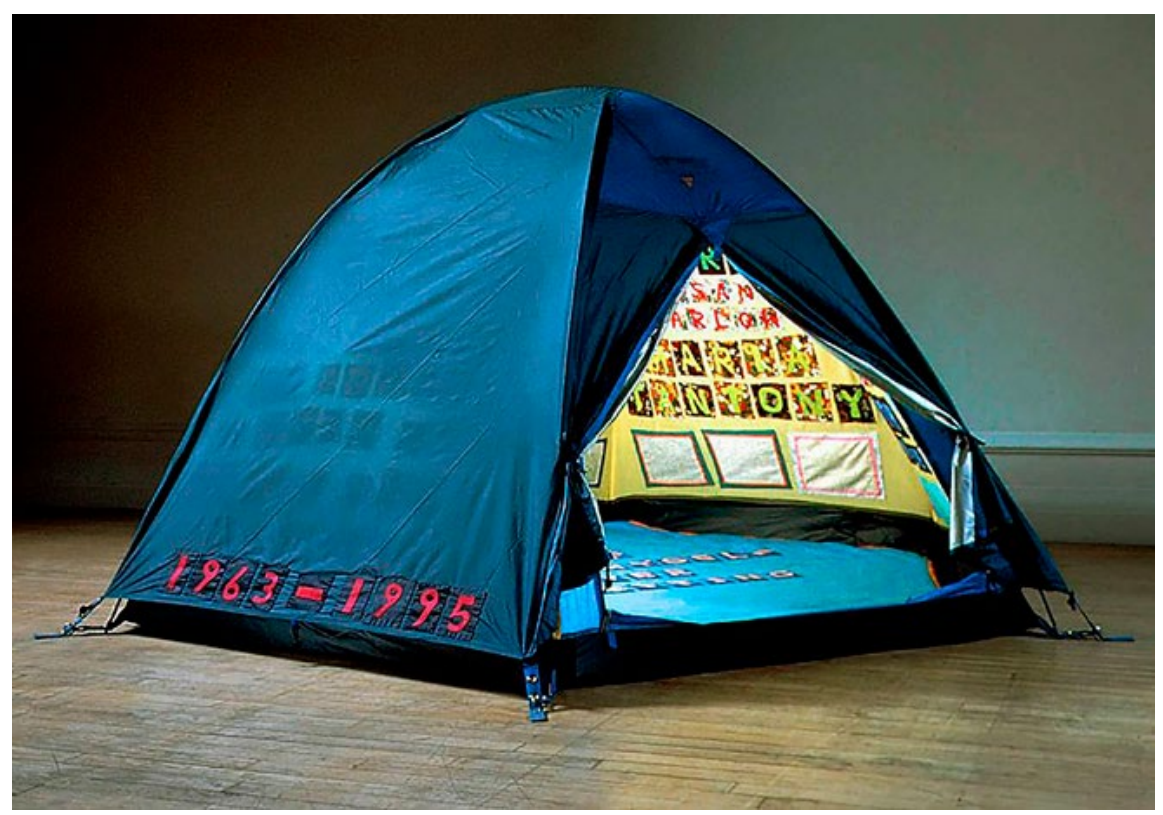

Figura 4 .

Feminismo/s 32, diciembre 2018, pp. 259-286 


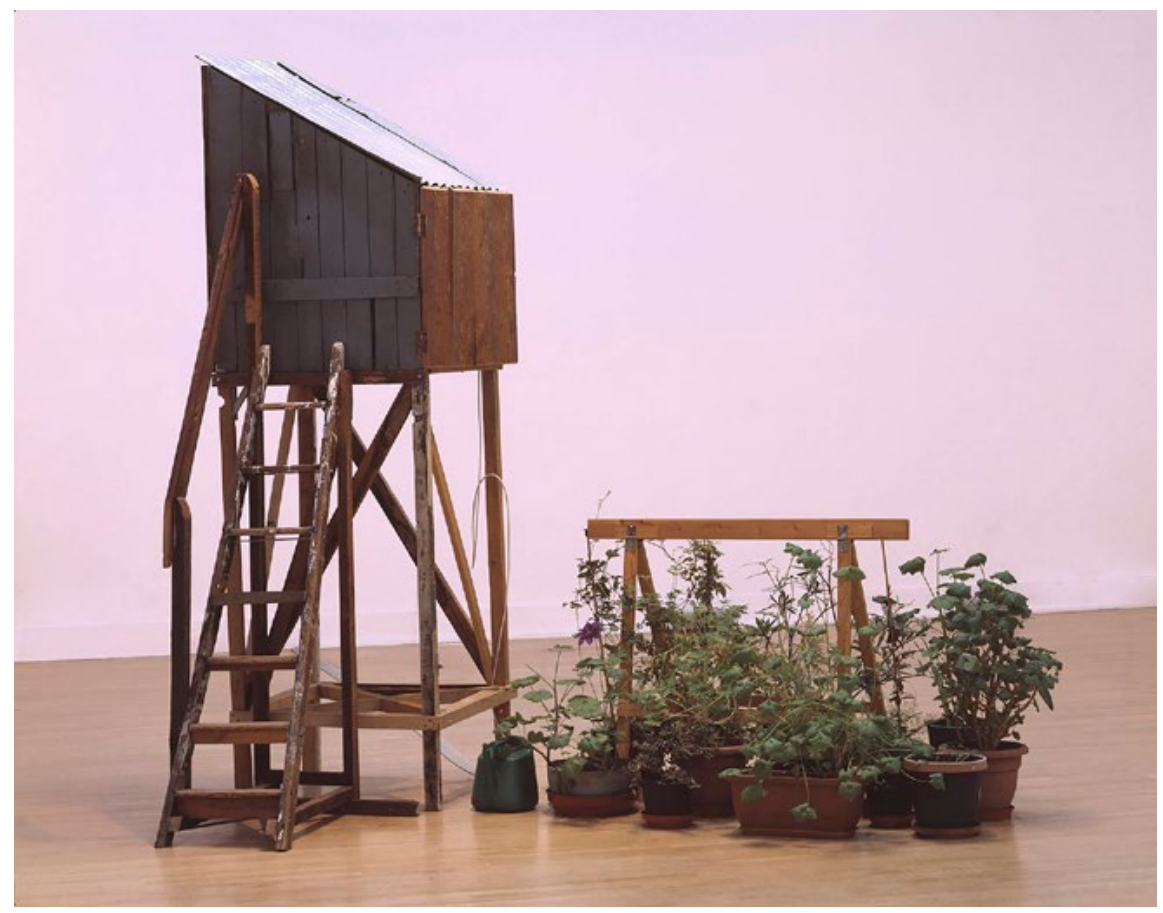

Figura 5.

vez, incluyendo los fetos de los dos abortos que había sufrido. La estructura de esta pieza, semejante al espacio cálido y femenino del útero, la impregna de un sentido de seguridad y habitabilidad del que carecen el resto de sus arquitecturas en las que la violencia convive con lo familiar en una simbiosis desgarradora.

En 2001 construye The Perfect Place to Grow [Fig. 5], una pequeña estructura de madera suspendida de un andamiaje que, a pesar de su fragilidad, invita al espectador a subir y mirar por un pequeño agujero situado en uno de los laterales de la casa. Dentro de la cabaña se proyecta un vídeo de su padre repitiendo una acción de forma ininterrumpida: se acerca de forma amable a la cámara para entregar una flor -a Emin- mientras sonríe, lanza un beso y vuelve a alejarse.

Feminismo/s 32, diciembre 2018, pp. 259-286 
La recodificación que la artista realiza del espacio doméstico y familiar en obras como Knowing my Enemy -2002-, o incluso It's Not The Way I Want To Die -2005-, no son más que reminiscencias de la casa natal que Emin reconstruye de forma obsesiva en un intento de reconciliarse con su propio pasado. Estas construcciones, difícilmente habitables, establecen un diálogo con otras obras protagonizadas por una serie de objetos domésticos como mantas, cartas, fotografías, test de embarazo, etc., que, desvinculados de su valor de uso, se han convertido «en eje de la receptividad psicológica del sujeto» (Baudrillard 27) y, por tanto, contenedor de aspectos relacionados con la intimidad de la propia artista. La epistemología visual que Emin establece con el espacio doméstico obedece a un desplazamiento de la narrativa hacia la arquitectura (Bal 44) y sus corolarios, gracias a la cual se despliega el discurso biográfico que parece ser la evidencia que trasciende en cada una de sus composiciones.

Por último, en las fotografías de Francesca Woodman, al igual que sucedía en la obra de Louise Bourgeois, la transferencia de la subjetivación de la propia artista en el interior doméstico parece convivir con la constante necesidad de escapar de él. En las obras de Woodman asistimos a una mise en abyme de la casa como trasunto de la identidad de la artista que, a través de una incansable exploración de las formas de habitar, se oculta, se camufla, se distorsiona, se suspende y se fragmenta en un ejercicio desfigurativo y sintomático del sujeto en el espacio. Y es que, aunque Woodman sea principio y fin de su obra, nunca aparece realmente retratada. En lugar de ello, y como producto de esta simbiosis entre el interior doméstico y ella misma, parece confundirse -acaso fundirse- con las paredes desvencijadas, con los quicios de puertas y ventanas, con muebles y otros objetos domésticos. Esta relación íntima, cómplice, con los interiores domésticos queda evidenciada en fotografías como My House -1976- [Fig. 6], en la que la artista, inmóvil en el ángulo que ejerce de punto de fuga y envuelta en plásticos, parece confundirse con el resto de elementos arquitectónicos.

El sentido de habitabilidad en la obra fotográfica de Woodman se caracteriza por su carácter fragmentario. La artista, a modo de aparición, transfiere a todos y cada uno de los instantes y de los rincones del espacio arquitectónico, una interioridad que la excede. Cada estancia interior es un reflejo del propio ser de la artista, aun incluso cuando es difícil reconocerla en ellas.

Feminismo/s 32, diciembre 2018, pp. 259-286 


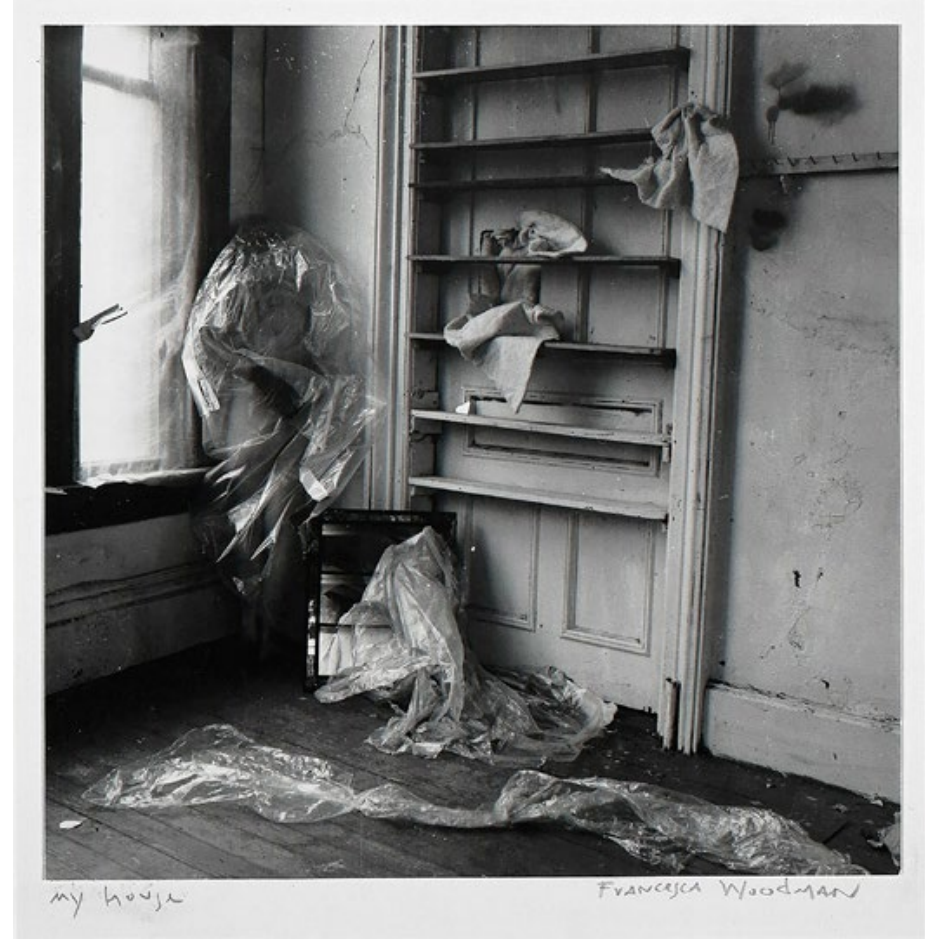

Figura 6.

Las imágenes de Woodman rebosan desasosiego y son representativas de un vértigo interior que acabó por desbordarla. La apropiación obsesiva y fantasmagórica que Woodam hace del espacio, junto con este culto a la ruina, a la sombra, al abandono y, en última instancia, al abismo, roza lo romántico y hace que los interiores aparezcan como espacios vivientes en el más estricto sentido de lo siniestro [Fig. 7]. La angustia que excede las imágenes que fotografía la artista mientras arranca el papel pintado de la pared, fija su sombra en el suelo, se esconde en el interior de una chimenea, introduce su brazo en un agujero de la pared, se refleja en un espejo o se suspende del dintel de una puerta, son reveladoras del alma de la artista.

En este caso, el interior doméstico únicamente puede ser comprendido como una extensión de la propia Woodman: la casa resulta un espacio a la 


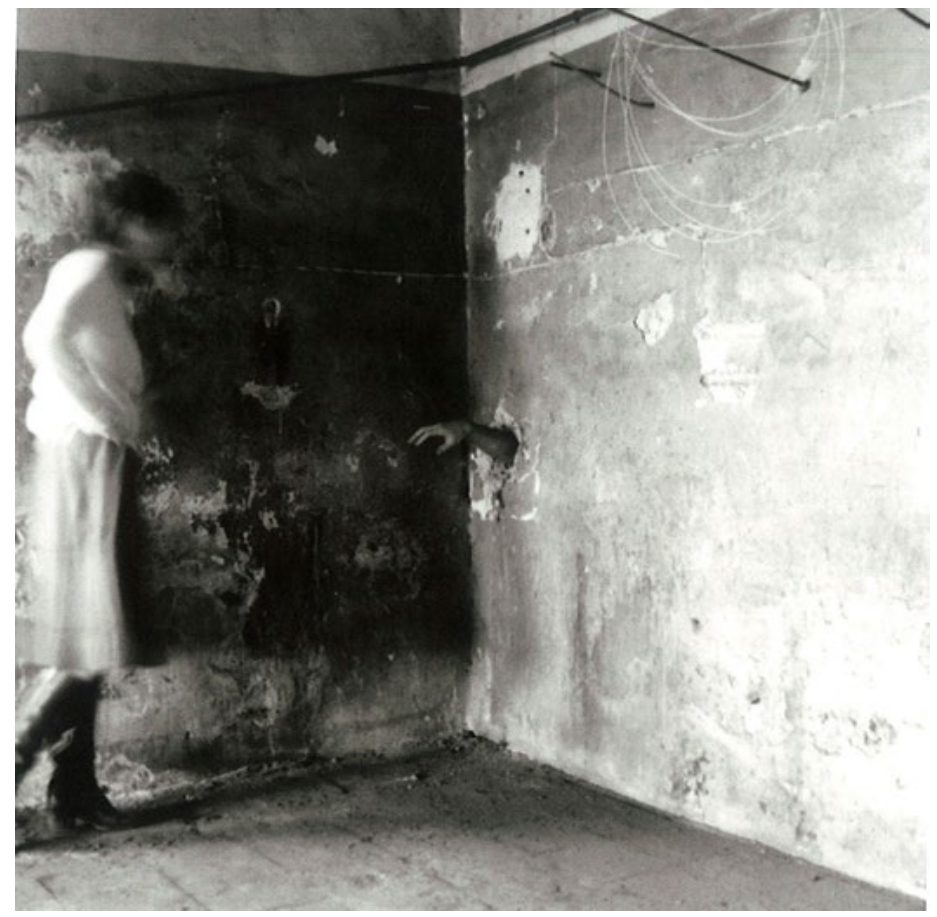

Figura 7.

vez de construcción y de reconocimiento de la identidad personal, de forma que experimentar la casa es experimentarse a uno mismo y viceversa (García Cortés 65).

En el caso de estas artistas, la arquitectura doméstica se muestra como un receptáculo en el que se vierte la memoria y la subjetividad, lo que revierte la concepción del espacio doméstico como el terreno natural en el que se despliega la felicidad familiar. Estas obras ponen en evidencia el papel redentor de la casa, que actúa como síntoma a la vez que como catarsis, garantizando un espacio narrativo mediante el que sostener la memoria individual y deconstruir la concepción de la mujer como ángel del hogar. 


\section{EL ARTE ES GARANTÍA DE CORDURA}

El siglo XX ha sido testigo de una de las mayores revoluciones acontecidas en relación a la mujer, sus derechos y sus competencias. A raíz de la llegada de la Tercera Ola feminista la relación, hasta entonces incontestable, de la mujer con la arquitectura doméstica entró en conflicto. Esta relación, que se había venido forjando desde el siglo XVII, se basó en la premisa de la capacidad innata de la mujer para hacer de la casa un espacio privado y afectivo. La permanencia de la idea del espacio doméstico como espacio natural de la mujer llevó a identificarla con el «alma» del hogar, categorizaciones que evidenciaban la perseverancia y la abnegación con la que la mujer debía ocuparse y, de hecho, se ocupaba, de la casa. Así, hasta mediados del siglo XX, el género determinó la forma de concebir el espacio doméstico, un espacio, a todas luces, anclado en una feminidad tan arcaica como recalcitrante.

Frente a este confinamiento de la mujer a la esfera privada y su labor de «crear hogar», durante la década de los setenta del siglo pasado surgieron toda una serie de propuestas, tanto activistas como artísticas, que posibilitaron la salida de la mujer del hogar y la creación de una identidad propia basada en los presupuestos de individualidad y subjetividad. La disrupción que las obras realizadas en aquellas décadas llevó aparejada, tenía que ver, precisamente, con la apertura de la perspectiva femenina a un espacio público que, hasta entonces, había estado dominado por un punto de vista androcéntrico y occidental, que se había aceptado, de forma inconsciente, como el único legítimo (Pollock 14). Las obras de arte realizadas por mujeres y sobre mujeres se asentaron de forma definitiva y se convirtieron en una herramienta que cuestionaba, al tiempo que revertía, las premisas en torno a la realidad femenina que hasta el momento se habían dado por sentadas.

A partir de este momento, la casa comenzó a deconstruirse bajo proposiciones no sólo políticas que desvinculaban a la mujer del binomio hogar-género, sino también fenomenológicas que abrían el espacio doméstico a nuevos paradigmas representacionales basados en una figuración más real y sostenible de la relación entre la mujer y la casa. Las obras de las artistas analizadas participan, indiscutiblemente, del axioma pronunciado por Louise Bourgeois, Art is guaranty of sanity -el arte es garantía de cordura-. Este enunciado, que aparece tanto en el frontispicio de la ya citada celda Precious Liquids -1992- como

Feminismo/s 32, diciembre 2018, pp. 259-286 
en multitud de bordados y grabados en los que, a modo de mantra, Bourgeois lo ha repetido a lo largo de su carrera artística, y que alude al efecto catártico y, en cierto modo, sanador, del arte.

A partir de esta premisa sostenemos que, en las obras de las tres artistas analizadas existe una renovada forma de entender tanto la práctica artística como la conexión entre la mujer y la casa. Este renovado vínculo, cimentado sobre una base autobiográfica, garantiza la permanencia de un futuro más razonable en la forma de entender la construcción doméstica a partir del género. Este nuevo nexo entre la mujer y la casa, que se establece a partir de la introyección de la subjetividad de una en el interior de la otra, no sólo legitima la capacidad de la mujer de reafirmarse a sí misma como sujeto individual, sino que, además, certifica la capacidad de transformación hacia una perspectiva más real y sostenible. Esta sostenibilidad está anclada en la facultad que estos proyectos artísticos tienen para expresar la realidad de la mujer en clave autobiográfica, que se revela como uno de los mecanismos preponderantes en occidente para elaborar la memoria histórica individual y la construcción de un imaginario doméstico en primera persona. Autoras como Leigh Gilmore, Celia Fernández Prieto, Anna Maria Guasch o, en este caso, Leonor Arfuch, han defendido la importancia que ha tenido la autobiografía de mujeres para producir un auténtico yo, eludiendo la teoría y basando la subjetividad en los detalles personales de su experiencia biográfica, con el fin de reafirmarse en una posición de sujeto que les otorga autoridad para reivindicar su propia verdad (96-97). Así, estas obras, cimentadas sobre la base de una exposición absolutamente pornográfica, se sirven de la memoria y de la experiencia femenina para, de forma simbólica, volver a habitar la casa y reconstruir la realidad doméstica en base a una función catártica y sanadora.

Como consecuencia de este mecanismo de retorno, la recuperación de la casa se desvela como un espacio siniestro. Lo siniestro, en los casos que nos atañen, está ligado tanto a la compulsión de repetición como a aquello que una vez fue familiar, pero ha llegado a resultar extraño e inhóspito. En este sentido, lo siniestro no es algo nuevo o ajeno al sujeto, sino algo que le es familiar y que, tras ser reprimido, ha sido recuperado por la conciencia. De este modo, lo siniestro no está sólo ligado a la incapacidad real del retorno y a la reconstrucción de la experiencia familiar a través de la memoria, sino

Feminismo/s 32, diciembre 2018, pp. 259-286 
que también está relacionado con la revelación de algo que hasta entonces se había mantenido oculto.

En su célebre ensayo acerca del carácter ominoso de la arquitectura, Anthony Vidler sostiene que la casa es el escenario de lo siniestro por antonomasia. Desde los relatos de Poe a las arquitecturas de la pintura romántica, la dimensión estética de lo siniestro se refiere a la proyección de un estado mental que elude los límites de lo real y lo irreal para provocar una ambigüedad inquietante (11). Así, la rehabitabilidad o recreación arquitectónica de lo doméstico que estas artistas llevan a cabo, revela la otrora familiaridad de la casa como un espacio extraño e inhóspito, como un escenario íntimamente relacionado con la nostalgia y con la proyección de una realidad que pertenece al ámbito de la memoria.

En definitiva, la arquitectura de la casa actúa como la protagonista indiscutible de las transformaciones biográficas, subjetivas e identitarias de la mujer. Así, la relevancia de este tipo de proyectos artísticos radica no sólo en desarticular las nociones preconcebidas en torno a la casa como un espacio idílico, sino también en concebir ésta como el escenario empleado por artistas como las citadas para comprender(se) y exponer(se) a través de la arquitectura doméstica. En este sentido, la función catártica que deviene de la proyección de la subjetividad femenina en la casa será la garantía de la continuación y redefinición de las formas de habitar y concebir el espacio doméstico.

\section{REFERENCIAS BIBLIOGRÁFICAS}

Amann, Atxu. El espacio doméstico: la mujer y la casa. Buenos Aires: Nobuko, 2011.

Arfuch, Leonor. Memoria y autobiografía. Exploraciones en los límites. Buenos Aires: Fondo de Cultura Económica, 2013.

Bachelard, Gastón. La poética del espacio. Buenos Aires: Fondo de Cultura Económica, 2000.

Bal, Mieke. Una casa para el sueño de la razón. (Ensayo sobre Bourgeois). Murcia: Cendeac, 2006.

Baudrillard, Jean. El sistema de los objetos. México: Siglo XXI, 1969.

Bauer, Nan. «Kitchen dramas». Heresies 3 (3) (1981): 42-46. 
Chicago, Judy y Miriam Schapiro. «Womanhouse Catalog Essay». Womanhouse. net. 21 marzo 2018.

Dalla Costa, Mariarosa y Selma James. El poder de la mujer y la subversión de la comunidad. Buenos Aires: Siglo XXI, 1977.

De Azcárate Ristori, José María, Alfonso Emilio Pérez Sánchez y Juan Antonio Ramírez Domínguez. Historia del Arte. Madrid: Anaya, 1993.

Díaz, Claudio. Vermeer. O la mujer, naturaleza muerta. Málaga: Servicio de Publicaciones de la Universidad de Málaga, 2001.

Emin, Tracey. Strangeland. The jagged recollections of a beautiful mind. Londres: Spectre, 2005.

Foucault, Michel. Historia de la sexualidad. Volumen I: La voluntad de saber. Madrid: Siglo XXI, 1993.

García Cortés, José Miguel. Políticas del espacio. Arquitectura, género y control social. Barcelona: Iaac (Institut d'Arquitectura Avançada de Catalunya), 2006.

Molina, Cristina. Dialéctica feminista de la Ilustración. Barcelona: Anthropos, 1994.

Neuman, Shirley. «Autobiografía: de una poética diferente a una poética de las diferencias». El gran desafío. Ed. Ángel G. Loureiro. Madrid: Megazul. Endymion, 1994. 417-439.

Otto, Rudolf. Lo santo. Lo racional y lo irracional en la idea de Dios. Madrid: Alianza, 2006.

Perry, Gill. Playing at Home. The House in Contemporary Art. Londres: Reaktion Books, 2013.

Pollock, Griselda. Visión y diferencia. Feminismo, feminidad e historias del arte. Buenos Aires: Fiordo, 2013.

Ramírez, Juan Antonio. Edificios-cuerpo. Madrid: Siruela, 2003.

Reckitt, Helena y Peggy Phelan. Arte y feminismo. Barcelona: Phaidon, 2005.

Rybczynski, Witold. La casa. Historia de una idea. Buenos Aires: Emecé, 1991.

Torre, Susana. «Space as Matrix». Heresies 3 (3) (1981): 51-52.

Smith, Sidonie. «Hacia una poética de la autobiografía de mujeres». El gran desafío. Ed. Ángel G. Loureiro. Madrid: Megazul.Endymion, 1994. 113-149.

Vidler, Anthony. The architectural uncanny. Essays in the modern unhomely. Massachusetts: Massachusetts Institute of Technology, 1992.

Wolf, Naomi. El mito de la belleza. Barcelona: Emecé, 1991. 


\section{FILMOGRAFÍA}

The Wizard of Oz. 1939. Estados Unidos, Dirección: Victor Fleming. Productora: Metro-Goldwyn-Mayer (MGM). 